\title{
Retrorectal cystic hamartoma: A case report
}

\author{
Ricardo Cabrita Viveiros, José Pinto Cruz, Rubina Lara Gouveia, \\ Ricardo Jorge Pestana, Jorge Miguel Fernandes, Maria José Olim
}

\begin{abstract}
Introduction: Retrorectal hamartomas are congenital lesions that typically present themselves as pre-sacred tumor masses. Clinical manifestations are light and highly variable at presentation time, often leading to diagnostic difficulties and surgical failure. Case Report: A case of 46-year-old female who is referred to neurosurgery by her medical assistant with a few months history of paresthesia and decreased left lower limb muscle strength and more recently symptoms of gastrointestinal disorders (constipation, tenesmus and feeling of false wills). Imaging studies revealed a pre-sacral tumor with suspicion of nerve dependence on S4 and cystic nature. She underwent partial resection of the capsule of the lesion and aspiration of its contents by multidisciplinary team abdominal approach (general surgery/ neurosurgery). The anatomopathological examination revealed a retrorectal cystic hamartoma. During follow-up the patient again developed tenesmus, false desires and
\end{abstract}

Ricardo Cabrita Viveiros ${ }^{1}$, José Pinto Cruz ${ }^{2}$, Rubina Lara Gouveia², Ricardo Jorge Pestana ${ }^{3}$, Jorge Miguel Fernandes ${ }^{4}$, Maria José Olim ${ }^{1}$

Affiliations: ${ }^{1} \mathrm{MD}$, Hospital Dr. Nélio Mendonça, Resident, General Surgery, Funchal, Madeira, Portugal; ${ }^{2} \mathrm{MD}$, Hospital Dr. Nélio Mendonça, Consultant, General Surgery, Funchal, Madeira, Portugal; ${ }^{3} \mathrm{MD}$, Hospital Dr. Nélio Mendonça, Consultant, Neurosurgery, Funchal, Madeira, Portugal; ${ }^{4} \mathrm{MD}$, Hospital Dr. Nélio Mendonça, Fellow, General Surgery, Funchal, Madeira, Portugal.

Corresponding Author: Ricardo Nuno Cabrita Viveiros, Travessa Manuel Alexandre, $n^{\circ} 7 \mathrm{~b}$, Funchal, Madeira, Portugal, 9060-189; Email: ricardoviveiros@hotmail.com

Received: 15 December 2016

Accepted: 09 February 2017

Published: 25 February 2017 the paresthesias of the left leg reappeared. The imaging tests confirmed a recurrence of the retrorectal hamartoma. The patient was again operated for block excision, this time by posterior approach. Conclusion: This case highlights the importance of retrorectal hamartomas as a differential diagnosis of presacral masses and it shows the difficulty in obtaining its diagnosis and treatment.

Keywords: Presacral space, Retrorectal cystic hamartoma, Tailgut cyst

\section{How to cite this article}

Viveiros RC, Cruz JP, Gouveia RL, Pestana RJ, Fernandes JM, Olim MJ. Retrorectal cystic hamartoma: A case report. Case Rep Int 2017;6:5-8.

Article ID: 100033CRINTRV2017

$* * * * * * * * *$

doi:10.5348/crint-2017-33-CR-2

\section{INTRODUCTION}

The retrorectal space is an uncommon location for the emergence of tumor masses and can include primary tumors of neurogenic, osteogenic or congenital origin and secondary tumors of metastatic or inflammatory origin. The congenital conditions include teratoma, chordoma, sacred anterior meningocele and cystic lesions (dermoid, epidermoid, hamartomas, etc.) [1]. Retrorectal hamartomas are congenital lesions that appear as an embryonic remainder of the large intestine (hindgut) and which are usually located in the pre-sacred space. Pre-sacred hamartomas can be a source of perirectal 
or perianal chronic symptoms and are often difficult to recognize and diagnose. Also, treatment is often poorly oriented, submitting the patient to multiple surgeries before a definitive diagnosis can be obtained [2, 3].

\section{CASE REPORT}

A 46-year-old female, without relevant personal or family background, presented with clinical condition started two years ago, characterized by an intermittent pain in the left hip joint accompanied by decreased muscle strength in the left leg. During the following six months, the patient started to have symptoms of gastrointestinal disorders (constipation, tenesmus and incomplete evacuation). A digital rectal examination did not reveal any relevant finding besides decreased muscle strength in the left leg. A computed tomography (CT) scan of the lumbar spine showed no significant changes. Pelvic magnetic resonance imaging (MRI) scan revealed a massive lesion $(65.5 \times 54.5 \times 96.5 \mathrm{~mm})$ occupying the pre-sacred space (from the top edge of $\mathrm{S}_{3}$ to the lower limit of the coccyx, exceeding it), with well-defined limits, multicystic and chambered aspect, which conditioned slight remodeling of the sacrum and extending over a more solid aspect component, through the $\mathrm{S} 4$ conjunction hole mingling with the nerve root - images compatible with cystic schwannoma or cystic retrorectal hamartoma (Figures 1A-D). After a multidisciplinary discussion of the case (neurosurgery and general surgery), the patient underwent partial resection of the mass and aspiration of its contents by abdominal approach (laparoscopy/ laparotomy). The postoperative period progressed uneventfully and the patient was discharged at the sixth postoperative day. Anatomopathological examination indicated that the mass was a tailgut cyst, also designated
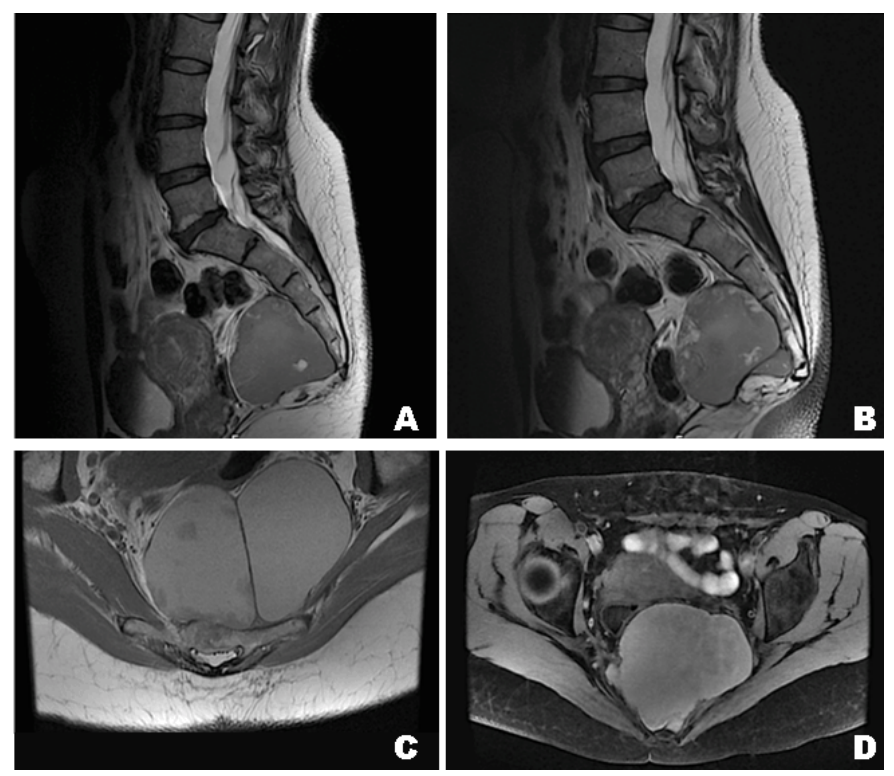

Figure 1: (A-D) Pelvic magnetic resonance imaging scan revealed a massive lesion $(65.5 \times 54.5 \times 96.5 \mathrm{~mm})$ occupying the pre-sacred space. as retrorectal cystic hamartoma. During follow-up the patient again developed tenesmus, false desires and the paresthesias of the left leg reappeared. A new pelvic MRI control was requested (25/05/2016) which revealed complex cystic lesion recurrence of pre-sacred space measuring now $88 \times 105 \times 78 \mathrm{~mm}$ conditioning a right anterolateral deviation of the rectosigmoid segment of the colon, but without extrinsic compression causing decrease in the size. The patient was again submitted to surgery for "en bloc" mass excision by posterior approach with coccygectomy Kraske procedure.

\section{DISCUSSION}

The retrorectal region is a potential space that may develop in the presence of a mass which is delimited superiorly by pelvic peritoneal reflection, inferiorly by the coccygeal and elevator muscles of the anus, anteriorly by the rectum, posteriorly by the sacrum and the coccyx and laterally by the iliac vessels, and ureters $[1,2,4]$. The differential diagnosis of masses that can develop in this area is vast and includes primary tumors of neurogenic, osteogenic and congenital origin, and inflammatory and metastatic secondary processes. Congenital lesions are rare and include chordoma, teratomas, anterior sacral meningocele and cystic lesions (dermoid, epidermoid, enteric duplication and hamartomas) [5]. The diagnostic imaging (MRI scan and CT scan) are the mainstay for diagnosing pre-sacred masses, and MRI scan is considered the best imaging exam to characterize the type of mass present in this space. All other complementary diagnostic tests only serve to increase the suspicion of a mass. However, definitive diagnosis and treatment can only be achieved with the complete excision. The preoperative biopsy is not advised because of the risk of spread of dysplastic cells, unless the mass is considered unresectable at presentation time.

So, it will be the different histopathologic features present in the anatomopathological examination that will allow to differentiate the kind of cyst. Dermoid and epidermoid cysts have stratified squamous epithelium, and only dermoid cysts may contain dermal appendages (hair follicles, sudoriferous glands or teeth). Enteric duplication is characterized by typical gastrointestinal epithelium and the presence of smooth muscle cells with nerve plexuses. Paracolorectal hamartomas may have different types of epithelium (columnar, squamous or transition) are often multicystic and may contain smooth muscle, but unlike enteral duplication the smooth muscle is disorganized and does not show nerve plexuses.

Surgical removal is recommended in both symptomatic and asymptomatic patients because of the possibility of malignancy, malignant transformation, infection and defecation difficulties. Various types of surgical approaches are described in the literature ranging from transabdominal (laparotomy or laparoscopy), trans-sacral intersphincteric, transsphincteric, parasacrococcygeal 
or trans-anal. Historically, the anterior, posterior or combined approach is chosen depending on the position of the mass $[6,7]$. Thus, if the mass is proximal to $\mathrm{S}_{3}$ the most appropriate approach will be the abdominal (especially if there is neoplasm suspicion), if the mass is distal to $\mathrm{S}_{3}$ the most suitable approach is posterior and if the mass is lying proximal and distal to $\mathrm{S} 3$ the approach should be combined [8, 9]. The surgical approach will also be influenced by the experience of the surgical team as this is a very uncommon pathology [10].

The follow-up of these patients should be done annually with physical examination including digital rectal exam and a CT scan should be performed at the first and fifth years after the surgery.

\section{CONCLUSION}

Retrorectal hamartomas should always be a diagnosis to bear in mind in the differential diagnosis of pararectal masses and their complete surgical removal is important in order to avoid recurrence and the risk for malignant transformation.

$* * * * * * * * *$

\section{Author Contributions}

Ricardo Cabrita Viveiros - Substantial contributions to conception and design, Acquisition of data, Analysis and interpretation of data, Drafting the article, Revising it critically for important intellectual content, Final approval of the version to be published

José Pinto Cruz - Substantial contributions to conception and design, Acquisition of data, Analysis and interpretation of data, Drafting the article, Revising it critically for important intellectual content, Final approval of the version to be published

Rubina Lara Gouveia - Substantial contributions to conception and design, Acquisition of data, Analysis and interpretation of data, Drafting the article, Revising it critically for important intellectual content, Final approval of the version to be published

Ricardo Jorge Pestana - Substantial contributions to conception and design, Acquisition of data, Analysis and interpretation of data, Revising it critically for important intellectual content, Final approval of the version to be published

Jorge Miguel Fernandes - Substantial contributions to conception and design, Acquisition of data, Analysis and interpretation of data, Drafting the article, Revising it critically for important intellectual content, Final approval of the version to be published

Maria José Olim - Analysis and interpretation of data, Drafting the article, Drafting the article, Final approval of the version to be published

\section{Guarantor}

The corresponding author is the guarantor of submission.

\section{Conflict of Interest}

Authors declare no conflict of interest.

\section{Copyright}

(C) 2017 Ricardo Cabrita Viveiros et al. This article is distributed under the terms of Creative Commons Attribution License which permits unrestricted use, distribution and reproduction in any medium provided the original author(s) and original publisher are properly credited. Please see the copyright policy on the journal website for more information.

\section{REFERENCES}

1. Patsouras D, Pawa N, Osmani H, Phillips RK. Management of tailgut cysts in a tertiary referral centre: A 10-year experience. Colorectal Dis 2015 Aug;17(8):724-9.

2. Suhani, Meena K, Ali S, Aggarwal L, Thomas S. Retrorectal cystic hamartoma: A problematic 'Tail'. J Surg Tech Case Rep 2014 Jul-Dec;6(2):58-6o.

3. Abukar AA, Parcell BJ, Lim CB, et al. Malignancy within a tail gut cyst: A case of retrorectal carcinoid tumour. Case Rep Surg 2014;2014:454502.

4. Chhabra S, Wise S, Maloney-Patel N, Rezac C, Poplin E. Adenocarcinoma associated with tail gut cyst. J Gastrointest Oncol 2013 Mar;4(1):97-100.

5. Haydar M, Griepentrog K. Tailgut cyst: A case report and literature review. Int $\mathrm{J}$ Surg Case Rep 2015;10:166-8.

6. Wolpert A, Beer-Gabel M, Lifschitz O, Zbar AP. The management of presacral masses in the adult. Tech Coloproctol 2002 Apr;6(1):43-9.

7. Woodfield JC, Chalmers AG, Phillips N, Sagar PM. Algorithms for the surgical management of retrorectal tumours. Br J Surg 2008 Feb;95(2):214-21.

8. Chéreau N, Lefevre JH, Meurette G, et al. Surgical resection of retrorectal tumours in adults: Longterm results in 47 patients. Colorectal Dis 2013 Aug;15(8):e476-82.

9. Prasad AR, Amin MB, Randolph TL, Lee CS, Ma CK. Retrorectal cystic hamartoma: Report of 5 cases with malignancy arising in 2. Arch Pathol Lab Med 2000 May;124(5):725-9.

10. Jao SW, Beart RW Jr, Spencer RJ, Reiman HM, Ilstrup DM. Retrorectal tumors. Mayo clinic experience, 1960-1979. Dis Colon Rectum 1985 Sep;28(9):64452. 
Access full text article on other devices

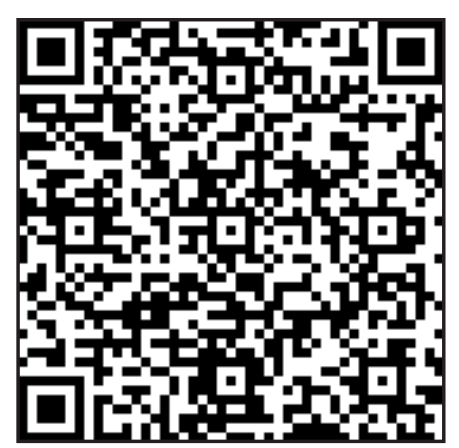

Access PDF of article on other devices

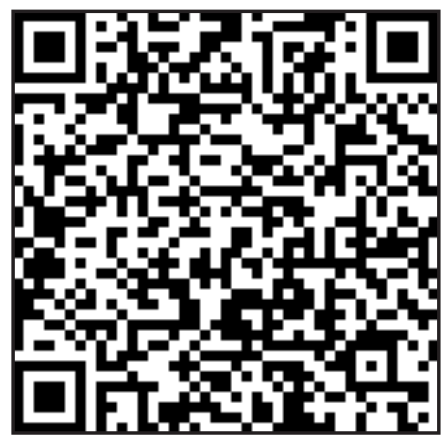

